\title{
E. coli OI57 outbreaks in the United Kingdom: past, present, and future
}

\author{
This article was published in the following Dove Press journal: \\ Infection and Drug Resistance \\ 19 August 2014 \\ Number of times this article has been viewed
}

\section{Thomas Hugh Pennington \\ University of Aberdeen, Aberdeen, United Kingdom}

\begin{abstract}
This review describes Escherichia coli 0157 outbreaks in the United Kingdom, beginning from the first, in the 1980s, to those recorded in 2013. We point out that the United Kingdom differs from other countries, particularly the United States, in that it has had a considerable number of outbreaks associated with butchers, but very few caused by contaminated burgers. Two of the butcher-associated outbreaks (in central Scotland in 1996 and South Wales in 2005) were very large and are considered here in detail; the reviewer conducted detailed investigations into both outbreaks. Also considered is the very large outbreak that occurred in visitors to an open farm in Surrey in 2009. Detailed descriptions of some milk-borne outbreaks and incidents connected with camping and childrens' nurseries have been published, and these are also considered in this review. Large outbreaks in the United Kingdom have sometimes led to policy developments regarding food safety, and these are considered, together with public reactions to them, their health effect, and their value, as examples to follow or eschew in terms of the procedures to be adopted in response to incidents of this kind. Regulatory and legal consequences are also considered. As a wise man said, making predictions is difficult, particularly about the future. This review follows this position but points out that although human infections caused by E. coli $\mathrm{O} 157$ are rare in the United Kingdom, their incidence has not changed significantly in the last 17 years. This review points out that although a response to an outbreak is to say "lessons must be learned", this response has been tempered by forgetfulness. Accordingly, this review restricts its recommendations regarding outbreaks to two: the crucial importance of a rapid response and the importance of experience, and even "gut feeling", when an inspector is evaluating the safety of a food business.
\end{abstract}

Keywords: E. coli O157, outbreaks, UK

\section{Introduction}

Theodor Escherich in Munich in 1885 was the first to grow Escherichia coli in pure culture. He also showed that it was a normal inhabitant of the intestines of infants. ${ }^{1}$ About 100 billion billion E. coli are alive in the world at any one time, and the overwhelming majority are harmless commensals. However, some are pathogenic. This review considers outbreaks of disease in the United Kingdom caused by E. coli $\mathrm{O} 157$, one of the most important pathogens with this specific identity and a member of a group of organisms known variously as enterohemorrhagic, verocytotoxin-producing, or Shiga toxin-producing E. coli. ${ }^{2}$

Most E. coli $\mathrm{O} 157$ strains produce Shiga toxin type 2; its B subunits bind to the surface of intestinal cells, and its A subunits enter and turn off protein synthesis by disrupting the large ribosomal subunit. Bloody diarrhea is a hallmark of symptomatic

\section{Correspondence: TH Pennington}

13 Carlton Place, Aberdeen ABI5 4BR, United Kingdom

Email mmb036@abdn.ac.uk 
cases; a minority of patients, usually at the extremes of age, develop hemolytic uremic syndrome (HUS), in which thrombocytopenia and renal failure usually occur. Neurological and cardiac complications are important determinants of mortality. ${ }^{3}$

Human infections are zoonotic; E. coli $\mathrm{O} 157$ is a normal nonpathogenic intestinal commensal in ruminants. ${ }^{4}$

\section{Outbreaks}

Outbreaks in the United Kingdom (generally defined as two or more cases from separate households linked to a common source) are investigated by outbreak control teams (OCTs). Factors that lead to the declaration of an outbreak and the establishment of an OCT are one or more of the following: an immediate and/or continuing health hazard to the local population, one or more cases of serious disease, large numbers of cases, and the involvement of more than one local authority. OCT members include public health specialists, local authority environmental health officers, and health service staff. Their main functions are to manage the outbreak, to draw lessons, and to prepare a report. Many reports only circulate locally; a few are published in the scientific literature. Occasionally, accounts are published as the outcome of nonstatutory inquiries commissioned by an interested party, such as the review of the major outbreak of E. coli O157 in Surrey in 2009 (the Godstone Farm outbreak). ${ }^{5}$ Statutory inquisitorial inquiries include fatal accident inquiries (Scotland only) and public inquiries. Prosecutions in the United Kingdom are adversarial.

\section{The first E. coli OI57 outbreaks}

Outbreaks of bloody diarrhea in 1982 in the United States marked the sudden appearance of E. coli $\mathrm{O} 157$ as a new pathogen, with 25 cases in Medford, Oregon, in February and March, and 18 cases in Traverse City, Michigan, in May and June. The organism was isolated from four cases in each outbreak. There was a strong epidemiological link to the consumption of beef burgers. ${ }^{6}$

E. coli $\mathrm{O} 157$ was first isolated during an outbreak in the United Kingdom in July 1983, when stools from three patients tested positive in a cluster of 11 cases of HUS in children from Wolverhampton in the West Midlands. ${ }^{7}$ It was a pathogen new to the United Kingdom. A retrospective search of more than 15,000 E. coli strains collected between 1978 and 1982 revealed only one isolate, and it was not found in any of the 161 diarrhea outbreaks investigated by the Reference Laboratory of the Public Health Laboratory Service for England and Wales between 1973 and $1983 .^{6}$

\section{Outbreaks in the United Kingdom, 1985-1996}

The first community outbreak in adults in the United Kingdom occurred in July 1985, when 49 people fell ill in East Anglia, 19 of whom were admitted to hospital. Bloody diarrhea and severe abdominal pain dominated. Three patients had laparotomies, and one woman (aged 64 years) died from fulminant colitis. Thirty-eight cases were women. E. coli $\mathrm{O} 157$ was isolated from the stools of 24 cases; their mean age was 43 years. The investigators found no link with the consumption of beef burgers (three of the confirmed cases were vegetarians) but suspected that handling foods followed by hand-to-mouth transmission rather than foodborne infection had occurred. A case-control study showed a strong association between infection and the preparation of raw vegetables, especially potatoes. ${ }^{8}$

In England and Wales, at least 55 outbreaks were reported between 1983 and 1996, and between 1989 and October 1996, there were 24 outbreaks in Scotland. ${ }^{9}$ Microbiologically confirmed sources included animal contact at a farm visitor center and cheese. Particularly good data came from Wales, which in 1990 had introduced universal testing for E. coli O157 for all first-time acute-phase fecal specimens. ${ }^{10} \mathrm{By}$ 1998, 415 cases had been reported, 46.3\% with blood in their stools. The majority of cases $(82.2 \%)$ did not occur in outbreaks. Six outbreaks occurred during this period: four with the mode of spread being person to person (two in institutions caring for psychogeriatric patients and two in day nurseries) and one being spread by contaminated meat.

\section{Heuristically important outbreaks in Scotland in 1990 and 1994}

The Hartwoodhill Hospital outbreak occurred in October $1990 .{ }^{11}$ Eight patients and three staff members in this small psychogeriatric hospital in Lanarkshire were infected. Four patients died. A fatal accident inquiry was held in 1991. This process requires a sheriff (a district judge) to make a determination in respect of a death, "setting out the circumstances of the death as far as they have been established to his satisfaction", including "the reasonable precautions, if any, whereby the death and any accident resulting in the death might have been avoided, and the defects, if any, in any system of working which contributed to the death or any accident resulting in the death". The sheriff concluded that an infection control nurse "could reasonably have been expected to ensure that the justifiable criticism of lax hygiene in the uplifting of soiled laundry, of unsafe standards of cleanliness 
in the wards and their furnishings, and of poor standards of housekeeping in the washing up of cleaning bowls and utensils would not have been levied".

The West Lothian (Redhouse Dairy) milk-borne outbreak occurred in May 1994. ${ }^{12}$ It affected a rural community to the west of Edinburgh. The dairy obtained milk from outlying feeder farms and pasteurized, bottled, and delivered it to more than 1,000 domestic customers and some retail outlets. More than 100 people were infected. One child died early in the outbreak, and 24 were admitted to hospital. Their average length of stay was just over 25 days. Ten children developed HUS, and six needed dialysis. Isolates of E. coli $\mathrm{O} 157$ were made from the stools of 69 patients, a section of pipe connecting the pasteurizer to the bottling apparatus, a bottling machine rubber, raw milk from a bulk carrier from a farm that supplied the dairy, and bovine feces from the same farm. All the isolates had the same pulsed field gel electrophoresis (PFGE) type, which was different from that of other strains being isolated in Scotland at that time. This influenced the sheriff at the criminal trial. Despite the defense taking the line that "there was not sufficient evidence of a credible and reliable nature to establish that milk sold or deposited for sale was contaminated with $E$. coli $\mathrm{O} 157$ organisms", the accused were found guilty of selling contaminated milk. Not only was this one of the earliest outbreaks in the United Kingdom to be investigated by PFGE of isolates, it was the first recorded anywhere in the world to involve a heat-treated milk supply. Its heuristic importance also comes from it being the subject of a detailed economic and social assessment of its effect on the infected and their families, hospitals and primary and community care facilities, public health departments, laboratories, environmental health departments, and veterinary services not only during the outbreak but also for the following 12 months. ${ }^{13}$ One year after the outbreak, one child had had a renal transplant and two still had no renal function and were receiving peritoneal dialysis; one of these children had developed insulin-dependent diabetes, and the other required intermittent nasogastric feeding. Two other children had reduced renal function. The medical, productivity loss, and outbreak control costs were estimated to be $£ 3.2$ million for the first year. Over the course of 30 years, the costs were projected to be $£ 11.9$ million. This outbreak ranks fourth in case numbers in the United Kingdom to date.

\section{Other milk-borne outbreaks}

The North Cumbria milk-borne outbreak ranks third in case numbers in the United Kingdom. ${ }^{14}$ It affected 114 individuals in late February and early March 1999; 88 had E. coli 0157 confirmed by laboratory tests. Twenty-eight were admitted to hospital, and three nursery school-age children developed HUS, recovering after hemodialysis. The milk came from a farm with 65 cows in milk. About 600 pints were pasteurized on Sundays, Tuesdays, and Thursdays and went to 321 premises, including 11 commercial establishments. The pasteurizer on the farm was of an old type that had been the subject of a food hazard warning the previous year. New heat exchanger plates had been fitted by the farmer a few days before the outbreak, but there was no record of subsequent tests. There was also failure in the automatic recording of flow diversion activity and inadequate temperature monitoring. It was likely that heat-treated milk was being contaminated with raw milk at the heat exchanger unit. Although milk samples did not grow $E$. coli $\mathrm{O} 157$, the organism was recovered from calf pen straw bedding, slurry samples, the floors of pens housing animals, and 11 animal feces samples. All these isolates had the same or very similar PFGE patterns as the human outbreak isolates. The farmer pleaded guilty when prosecuted by the local authority for the sale of milk unfit for consumption and for breaches of the regulations concerning the operation of pasteurizers.

During 1992-2000, E. coli O157 was the most common cause of milk-borne general outbreaks of infectious intestinal disease in England and Wales. ${ }^{15}$ It was the causative agent in nine outbreaks; Campylobacter caused seven outbreaks, Salmonella typhimurium six, Salmonella enteritidis pt4 two, other salmonellas two, and Cryptosporidium one. Five of the E. coli $\mathrm{O} 157$ outbreaks were ascribed to the consumption of unpasteurized milk, one to pasteurized milk that had been mixed with unpasteurized milk, and three to milk sold as pasteurized. Small farm dairies that bottled their own milk were identified as a significant problem. Unlike large dairies, which conducted the alkaline phosphatase test on all batches, during this period, small on-farm dairies did not do daily tests.

\section{The 1996 central Scotland outbreak}

Outbreaks of intestinal infectious disease associated with butchers' premises were not rare before 1996. Some were very big, such as the enormous North Wales and Cheshire outbreak during the summer of 1989. Caused by Salmonella typhimurium DT 12, it affected 640 people, with 74 hospital admissions and three deaths. ${ }^{16}$ In 1995, there were eight butcher-associated outbreaks in England and Wales. ${ }^{17}$

The central Scotland outbreak occurred in November and December 1996. The first evidence of infection was the identification of a presumptive E. coli $\mathrm{O} 157$ strain from a 
5-year-old child with bloody diarrhea on November $21 .^{18,19}$ Two more provisional identifications were made the next day, when the identity of the first isolate was confirmed. The microbiologist had been involved in the Hartwoodhill outbreak. He immediately considered that another outbreak was underway, because he considered his laboratory to be in a low-risk area and he had been screening feces for $E$. coli O157 for several years and had only made three isolates in the previous four years. He made further investigations and found that two other patients had been admitted to his hospital with bloody diarrhea and that another two with the same problem were in another local hospital. All lived in Wishaw, a small town in Lanarkshire, near Glasgow. By evening, the local public health department had identified 15 confirmed or suspected cases with E. coli O157. Eight had eaten food from J Barr and Son, Butchers, of Wishaw or had attended a church lunch in Wishaw at which food had been provided by Barrs. The number of cases increased dramatically. Eventually there were 503 cases, 279 of which were confirmed microbiologically (Figure 1). All isolates tested by PFGE had indistinguishable profiles. Cases were reported across central Scotland. The outbreak was made up of several separate incidents: the church lunch, a birthday party held in a public house on November 23, cases in a nursing home, and retail sales. Seventeen patients died directly of infection with the outbreak strain, and there were four associated deaths. The 74 attendees at the church lunch were the hardest hit (Figure 2). The lunch was for the elderly: eight died, and six developed renal failure. Their ages ranged

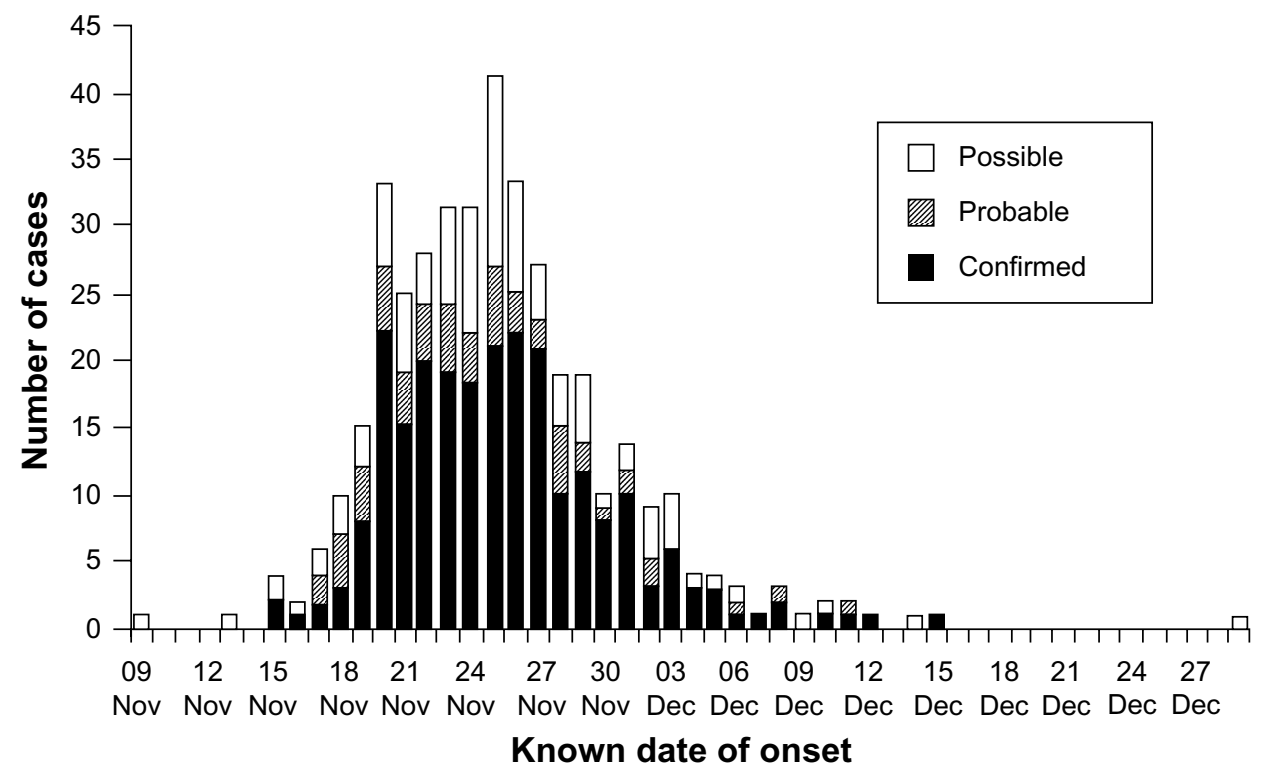

Figure I Epidemic curve, Central Scotland 1996 outbreak.

Note: Data from Pennington. ${ }^{20}$

Abbreviations: Nov, November; Dec, December.

Known date of onset from 70 to 83 years. The outcomes of infection contracted at the pub party were very different. Most of the 129 attendees were young (only 12 were aged 40 years or older). Of the 25 patients who were infected, 11 tested positive but had no symptoms. E. coli $\mathrm{O} 157$ was isolated from 10 members of Barr's staff, but only three had symptoms. The outbreak strain was isolated from the boiler used to cook the steak served at the church lunch; the butcher's vacuum packing machine; raw sirloin, sausage stewing steak, and legs of pork from within the Barr premises; gravy from the church lunch; cooked ham supplied to the pub for the party; roast beef; roast pork; and corned beef supplied by Barr to other firms. The butcher pleaded guilty in January 1998 on charges under the Food Safety Act and was fined a total of $£ 2,250$.

\section{The outbreak led to two inquiries}

The government in Scotland, the Scottish Office, established an expert group, chaired by the author, on November 28 , 1996. The outbreak was still in full progress. Its serious nature was already evident, in that five patients had already died. My group was charged "to examine the circumstances which lead to the outbreak ... and to advise [the Secretary of State for Scotland] on the implications for food safety and the lessons to be learned". Our final report was presented to parliament in April 1997. ${ }^{20}$ It concluded that measures were needed to reinforce legislation to strengthen the implementation and enforcement of the Hazard Analysis and Critical Control Point System (HACCP). The HACCP is a structured approach to analyzing the potential hazards in an operation, 


\section{Church lunch \\ 17th November 1996}

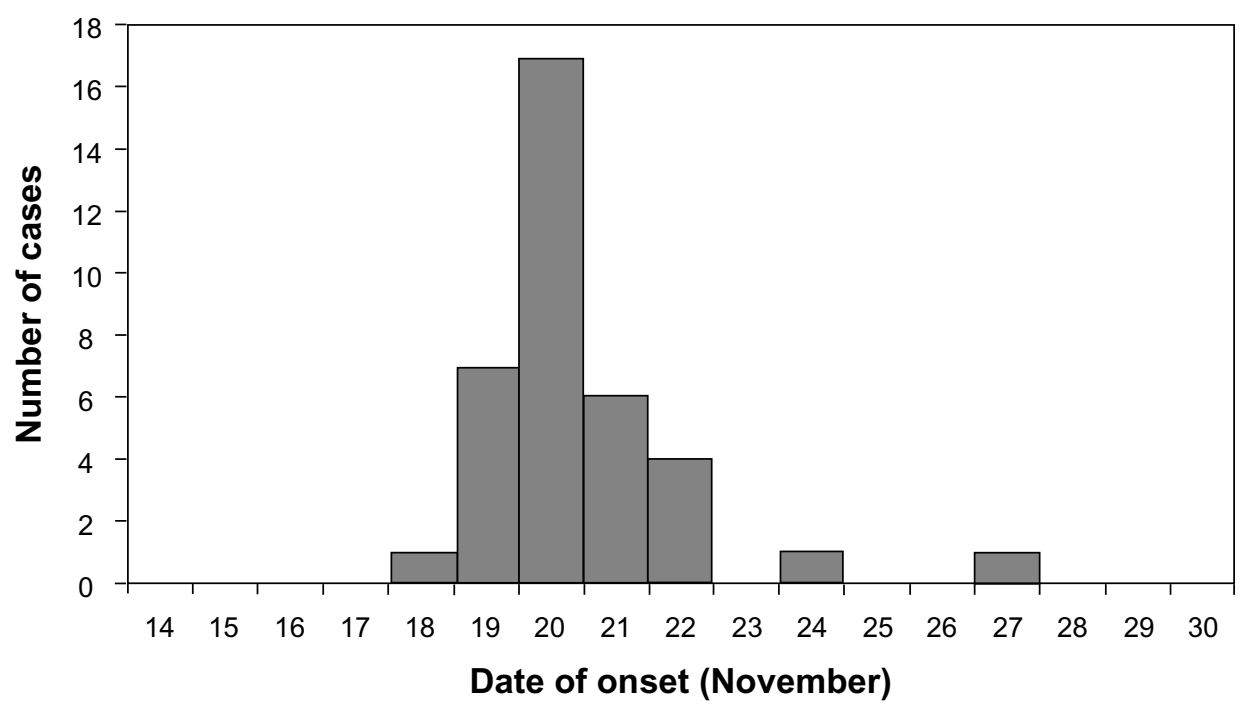

Figure 2 Epidemic curve, Church Hall component of the Central Scotland outbreak.

identifying the points in the operation where the hazards may occur, and deciding which points are critical to control to ensure consumer safety. These critical control points are then monitored, and remedial action, specified in advance, is taken if conditions at any point are not within safe limits. Verification procedures are established to confirm that the HACCP system is working effectively, and documentation of all procedures and appropriate records is done. My group recommended that all these HACCP principles be adopted by all food businesses. While this was being negotiated into EU and domestic legislation, selective licensing arrangements for premises selling raw and unwrapped cooked meats should be introduced. Licensing would require food handler training and arrangements for ensuring the physical separation of the raw and the cooked. Within a year, local authorities in Great Britain received $£ 19$ million to be spent over the course of 3 years to facilitate the acceleration of the HACCP. Butcher's licensing was introduced in Scotland and England in 2000, and in Wales and Northern Ireland in 2001, and remained in force until the beginning of 2006. Abattoirs were also considered. Recommendations to the Meat Hygiene Service included rigor in the rejection of dirty animals and the targeting of resources on higher-risk premises, particularly those with Hygiene Assessment scores below 65. ${ }^{17}$

A fatal accident inquiry established the details of what went wrong at the Barr premises. ${ }^{21}$ Set up in December 1996, the inquiry had to wait until criminal proceedings against John Barr had been concluded and did not begin until in April 1998. The sheriff made many criticisms of Barr's. He listed deficiencies under the heading of "defects in any system of working which contributed to the accident". Temperature probes were not being used to ensure the proper cooking of meat. Separate knives, work tables, scales, and vacuum packers for raw and cooked meats were not provided. There was no clear management structure to enforce food safety measures. And environmental health officers had failed to identify these food safety hazards. Detailed examples that the sheriff quoted were the defective boiler used to cook the meat served at the church lunch (two of its heating elements were not working), work flows in the premises allowing the crossing of raw and cooked meat processing, and the use of the same surfaces for handling raw and cooked meats (surfaces that were not being cleaned with bactericides).

\footnotetext{
What was being used was a biodegradable washing up liquid for cleaning work surfaces. The description 'biodegradable' in the eyes of Barr's senior staff was synonymous with 'bactericidal'. The liquid in use was green in color. There was no doubt about that. Mr Barr thought that about five years before the outbreak he had changed his supplier on the recommendation of a former employee who said that he could get a cleaning agent with the same properties at a more attractive price. If true this raises the question [...] how environmental health officers in the course of their inspections did not discover that a bactericidal agent was not being used. [Sheriff]
}

Studies in my laboratory showed that the "green biodegradable liquid" supported the growth of E. coli. Not long before the outbreak, Mr Barr had been voted "Scottish butcher of the year" by his customers. The sheriff summarized the situation: "I have no doubt Mr John Barr liked a clean 
shop and maintained a clean shop. What he failed to do was maintain a safe shop and the main ingredients of his failure was ignorance of the requirements which would produce that result." The outbreak occurred because of Barr's ignorance; it was big because his business was big. Outwardly a small local butcher, the business had about 40 employees, and at the time of the outbreak, it had a substantial wholesale and retail trade involving the production and distribution across central Scotland of raw and cooked meats and bakery products.

\section{The 2005 South Wales outbreak}

General outbreaks of intestinal infectious disease associated with butchers' premises continued in the United Kingdom after $1996 .{ }^{17}$ In England and Wales, there were four outbreaks in 1997, two in 1998, four in 1999, five in 2000, three in 2001, and one in 2004. There were none in 2002 and 2003. However, the expectation that butchers licensing and its associated focus on the implementation of HACCP would result in the prevention of butcher-associated outbreaks was dashed in South Wales in 2005. ${ }^{17}$ On September 16, a doctor at Prince Charles Hospital, Merthyr Tydfil, informed the National Public Health service for Wales that in the previous two days, five children had been admitted with bloody diarrhea and that three others with the same condition had been seen at the hospital assessment unit. That morning, microbiology reported that E. coli $\mathrm{O} 157$ had been isolated from two samples. An outbreak was declared that afternoon. At its end, 118 cases had been confirmed microbiologically and 39 were probable, in that the patients had developed bloody diarrhea during the outbreak period. The majority of cases were schoolchildren. Thirty-six primary and eight secondary schools in the local authority areas of Bridgend, Caerphilly, Merthyr Tydfil, and Rhondda Cynon Taf had at least one case; 25 schools had only one case, but two had the maximum recorded in the outbreak (eleven cases). Forty-eight cases were considered to be secondary infections (Figure 3). Thirty-one cases were admitted to hospital, eight with HUS.

One child died. Mason Jones was aged 5 years and had just started school. His illness began on September 21, with a fever. Diarrhea started on September 22, and a stool sample was taken. The diarrhea became bloody on September 23. Late on September 25, Mason was admitted to hospital. He had developed thrombocytopenia and had biochemical changes indicating the onset of renal failure. The stool sample result was positive for $E$. coli O157. Peritoneal dialysis started on September 26, but Mason had fits on September 27. He needed drugs to maintain his blood pressure and was being ventilated. Hemodialysis was started, and Mason's condition stabilized. His best renal day was October 1, when hemodialysis was not required; however, it was required again on October 3. At 5 pm, his blood pressure began to fall, dropping suddenly at $11 \mathrm{pm}$. Some cardiac function returned after external cardiac massage, but at midnight, there was a precipitous fall in blood pressure and a gradual drop in his heart rate. He became unresponsive, and resuscitation attempts stopped at 12.30 am on October 4.

On October 5, the National Assembly for Wales set up a cross-party committee to consider the terms of reference for

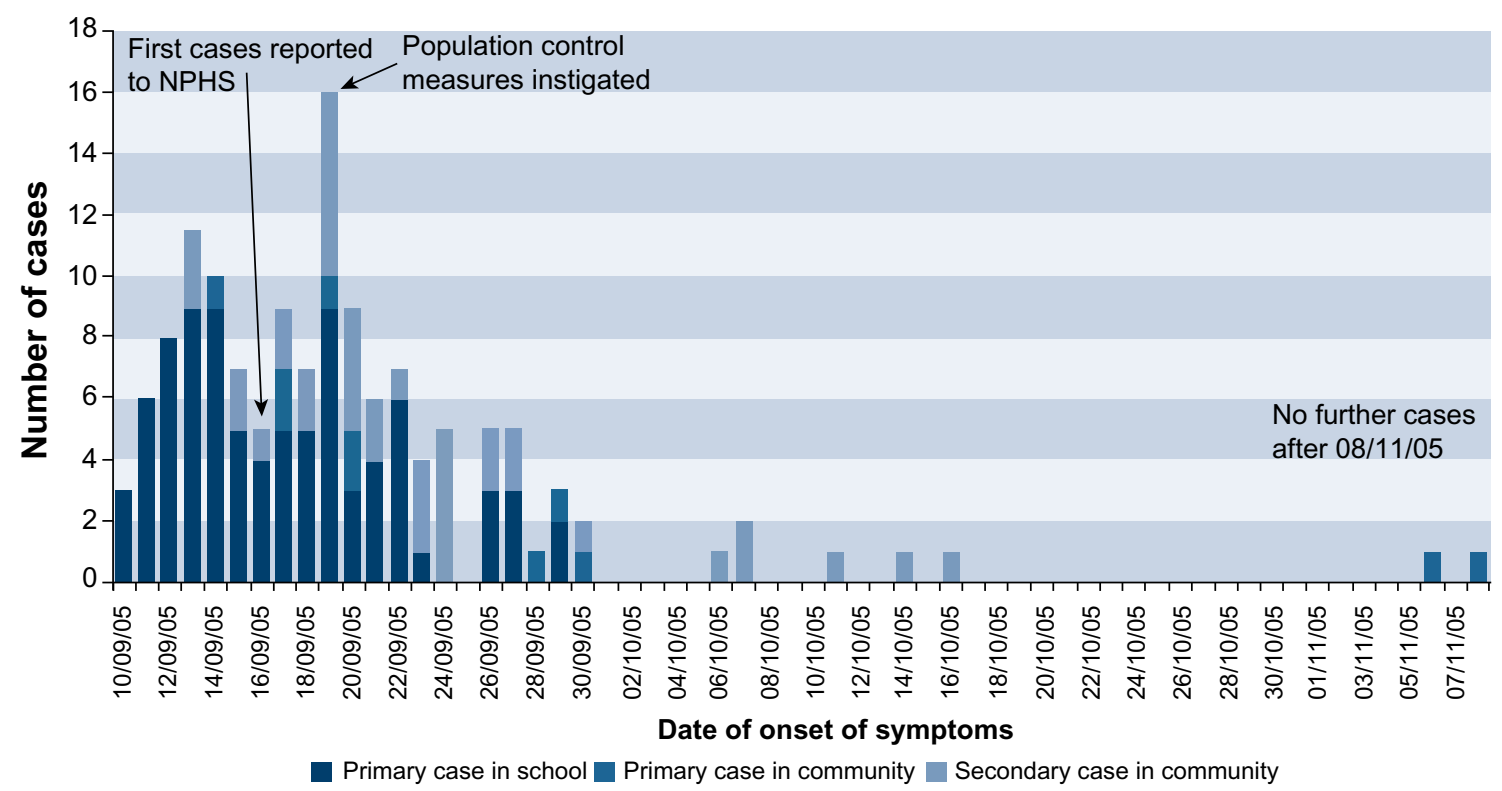

Figure 3 Epidemic curve, South Wales 2005 outbreak.

Notes: () Queen's Printer and Controller of HMSO; 2009. Pennington TH. The Public Inquiry into the September 2005 Outbreak of E. coli OI57 in South Wales. Aberdeen: HMSO; 2009. Available from: http://wales.gov.uk/ecolidocs/3008707/reporten.pdf? skip=I \&lang=en. ${ }^{17}$

Abbreviation: NPHS, Public Health Service for Wales. 
a public inquiry. It was formally established by the assembly under my chairmanship on December 7, 2005.

The common feature linking the cases was the supply of cooked, sliced meat from John Tudor and Son. The business supplied the school meals service in the four local authorities. All schools with a case where the onset of symptoms took place before September 17, 2005, had been exposed to cold cooked meats supplied by Tudors during the first week of term. Very similar PFGE profiles and indistinguishable variable number tandem repeat profiles were shown by all the strains tested from outbreak cases (including the one from Mason Jones), as well as strains isolated from unused cooked meat recovered from five schools, from a joint of raw meat recovered from John Tudor and Sons premises, and from cattle feces from the farm that supplied the abattoir that supplied meat to Tudors.

The abattoir was operated by Jonathan Tudor, a cousin of William Tudor, who ran the butcher's business known as John Tudor and Son. The abattoir was built in about 1860. In 1994, a scheme for scoring and assessing hygiene at abattoirs was introduced. Marks were out of 100 . Scores below 66 were deemed to be unacceptably low. In March, the Tudor abattoir scored 15 points. This score rose to 35 in July, but at an unannounced inspection in August, it had fallen to 11, the lowest score ever recorded in Great Britain. The government was advised to revoke the abattoir's license, but it continued to operate. A HACCP for plants such as the abattoir was introduced in 2003, but at the time of the outbreak, it had not been implemented at the abattoir. In essence, the problems identified in the early 1990s had not been rectified; the regulator, the Meat Hygiene Service, had failed to perform its enforcement function effectively.

John Tudor and Son sold raw and cooked meats. It cooked meats and produced faggots and burgers. Public sector organizations were major customers. Investigation of the business after the outbreak found many serious food hygiene deficiencies: Staff were poorly trained; single machines and equipment, including weighing scales, were being used for both raw and cooked meats; and cleaning was totally inadequate (eg, the probe wipes found on the premises had an expiry date of 1991, and machinery was usually cleaned with "truck wash traffic film remover"). For some products, the HACCP plan described a cooling rate after cooking that flouted the laws of physics. The plan also did not cover a major activity at the premises: the processing of bought-in cooked meats. Most staff members had not seen it or knew what the HACCP meant. A forensic scientist produced conclusive evidence that temperature records were not made contemporaneously but were made in batches at one time. The longest period written by one person in one ink was from July 28, 2004, to February 2, 2005, which are significant dates because on July 28, 2004, the premises had been inspected regarding butchers licensing, and on February 2, 2005, there had been a follow-up inspection after a January 18, 2005, inspection because in January, William Tudor had been unable to produce the records, saying they had been "taken home for updating". In saying this, he lied to environmental health officers. Even so, one environmental health officer noted in April 2001 that, "Records were being kept, systemic analysis, but couldn't help wondering whether some records were fixed as same style writing and color pen on many of the records." However, her note was not followed up by her successors. When meat went bad, William Tudor often directed his staff to reintroduce it into the food chain by removing the bad parts of a joint or by putting it into faggot mix, which hid the smell. In September 2007, he pleaded guilty to six offences of placing unsafe food on the market and one of failing to protect food against the risk of contamination. $\mathrm{He}$ was sentenced to 12 months imprisonment and prohibited from participating in the management of any food business in the future.

William Tudor's premises were inspected regularly by local authority environmental health officers. Their job was difficult because of his dishonesty, but they also failed to pick up fundamental flaws in the HACCP plan and defects in its implementation. William Tudor was issued with a butcher's license 6 weeks before the start of the outbreak. He should not have been.

My public inquiry report was published in March 2009. ${ }^{17}$ It made 24 recommendations, 15 of which focused on the HACCP and related issues. In response, the Food Standards Agency set up its Food Hygiene Delivery Programme, a 4-year implementation scheme.

\section{Outbreaks associated with farm visits/direct contact with manure}

Twenty-three outbreaks of E. coli $\mathrm{O} 157$ were linked to visits to open/petting farms in England and Wales between 1994 and 2008. ${ }^{22}$ The number of those affected in each outbreak averaged 7.7 cases. In Scotland, animal contact accounted for the largest single category of E. coli $\mathrm{O} 157$ outbreaks reported from 1996 to 2008.

A particularly tragic and costly outbreak occurred at an open farm in Hertfordshire, just north of London, in 1997.22 The farm had about 112,000 visitors annually. Hand-washing facilities were provided at the touching barn, the classrooms, and the restaurant. A boy, aged 7 years, who lived on the farm 
and who mucked out calf pens and had free access to all parts developed bloody diarrhea on May 10. He spent one week in hospital, and E. coli $\mathrm{O} 157$ was isolated from his stools. In addition, a 6-year-old girl who had visited the farm on June 3 and touched a number of animals fell ill on the June 6 and was admitted to hospital on June 10 with diarrhea and vomiting. She developed HUS, recovering with conservative management. Her stools were positive for $E$. coli $\mathrm{O} 157$. On June 30, a 4-year-old boy developed bloody diarrhea. E. coli $\mathrm{O} 157$ was isolated from his stools that had the same PFGE pattern as the strains from the other cases and from three isolates made on the farm from a goat paddock and one from a cow. The boy had visited the farm on June 27 and had clambered on fences and stroked animals. He was admitted to hospital on July 2 and developed HUS with severe neurological complications. He was in a coma for 12 days and was left unable to speak or eat and with epilepsy and spastic quadriplegia. Legal proceedings started. In January 2001 , a settlement of $£ 2.6$ million was agreed on. He died in April 2006.

A much larger outbreak occurred in Scotland in $2000 .^{23}$ A scout camp was held at the New Deer Agricultural Show Ground in Aberdeenshire to celebrate the Millennium. It was intended that the camp should run from Friday, May 26, to Sunday, May 28, but the camp was abandoned on May 27 because of very heavy rain. On June 1, a cub scout aged 8 years was admitted to the Royal Aberdeen Children's Hospital with gastroenteritis. His stools tested positive for E. coli $\mathrm{O} 157$, and the result was sent to the local communicable disease team on June 2. His attendance at the camp was noted, and the Scout Association was asked to compile a list of attendees. On June 4, a second child was admitted to Royal Aberdeen Children's Hospital with a probable diagnosis of $E$. coli O157. A public health doctor determined that other camp attendees were unwell, including an adolescent who had been admitted to the Infection Unit of Aberdeen Royal Infirmary with symptoms suggestive of an E. coli $\mathrm{O} 157$ infection. An outbreak was declared. The OCT was convened at $6 \mathrm{pm}$, and a press release was issued describing the scout camp as a potential link with cases of gastroenteritis, including one confirmed case of E. coli $\mathrm{O} 157$ infection. Of the 337 camp attendees, 20 tested positive for E. coli O157 (Figure 4), one of whom tested positive for Cryptosporidium as well. One scout developed HUS and needed dialysis. The attack rate for cub scouts, aged 8-11 years, was 8\% (11/145); for scouts, aged $12-16$ years, it was $9 \%(7 / 81)$; and for venture scouts, aged $17-25$ years, it was $9 \%(2 / 22)$. Dates when symptoms started ranged from May 28 (two cases) to June 3 (one case). Only $25 \%$ of the patients had bloody diarrhea. Food and drinking water were ruled out as risk factors, but attendees who did not wash their hands before meals were nearly nine times more likely to be ill with $E$. coli $\mathrm{O} 157$ than those who did. Until the day before the camp, 200 sheep had grazed the grounds, and it was heavily contaminated with feces as well as being waterlogged in places. E. coli $\mathrm{O} 157$ was isolated from feces, lying water, soil, Wellington boots, and a temporary climbing frame assembled for the camp; all had

\section{Millennium camp, New Deer}

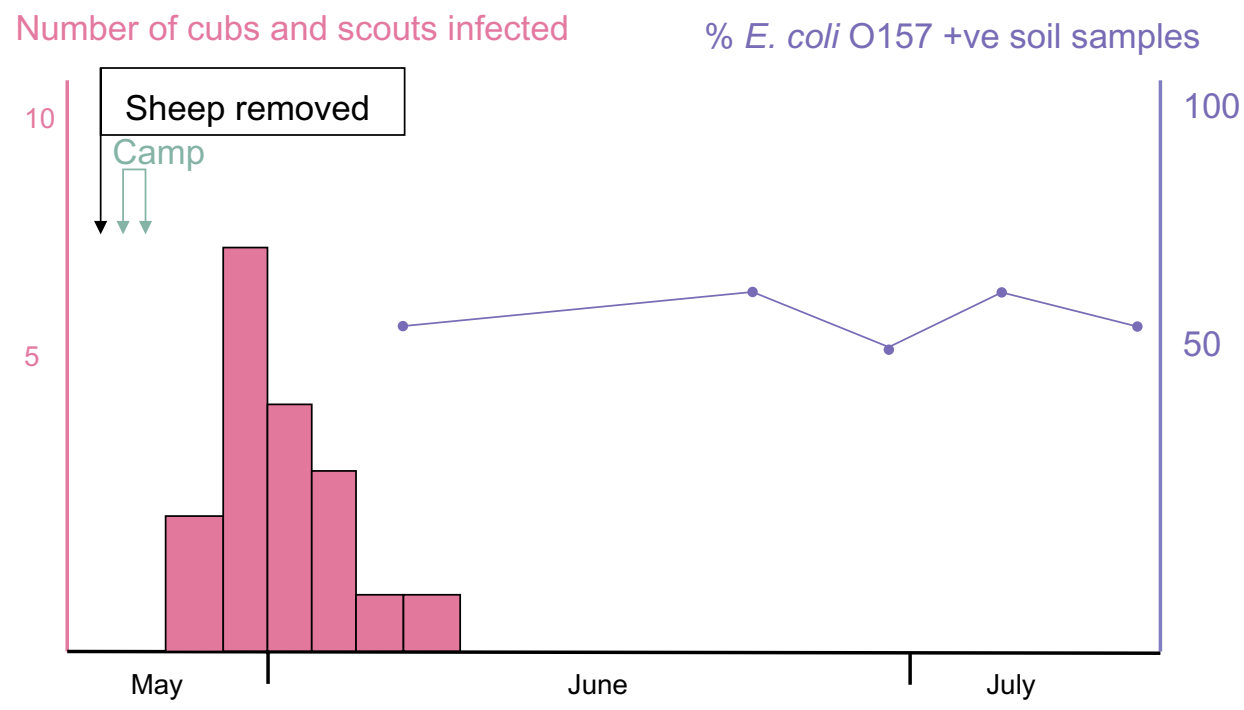

Figure 4 Epidemic curve, New Deer scout camp 2000 outbreak. 
the same PFGE type. A detailed study of the grounds after the outbreak concluded that about $50 \%$ of the sheep were excreting $E$. coli $\mathrm{O} 157$; ewes, on average, were excreting $8,400 / g$ organisms in their feces. One lamb was excreting more than a million organisms/gram. ${ }^{24}$

\section{The Godstone Farm outbreak, 2009}

The largest farm outbreak in the United Kingdom, and the largest to have been recorded anywhere else, occurred in England in 2009. ${ }^{5}$ Godstone Open Farm is in Surrey, to the south of London. In operation for more than 25 years, it had more than 200,000 visitors annually, employing 12 full-time staff with another 12 being taken on part-time at busy periods and 25-30 students being employed at weekends and school holidays. It had two animal petting barns, with the main one housing sheep, goats, pigs, a calf, and a Shetland foal, and the other housing goats, calves, and piglets. All the animals could be touched, and children were encouraged to play with lambs in the main barn. The farm was located in an area which the Surrey and Sussex Health Protection Unit of the Health Protection Agency (HPA) provided public health functions, and Tandridge District Council provided environmental health services. On August 20, the Surrey and Sussex Health Protection Unit was told by the South West London HPU about a child with presumptive E. coli $\mathrm{O} 157$ who had visited the farm on August 8, and on that day, another environmental health department informed Tandridge about two other cases. On August 26, the South East London HPU informed the Surrey and Sussex Health Protection Unit about another E. coli $\mathrm{O} 157$ case who had visited the farm on August 15 , and the next day, another case who had fallen ill on August 24 was reported to the HPU. Tandridge found that this patient had visited the farm on August 21. The farm was advised about extra signage.

The weekend of August 29-31 was a public holiday. On September 1, Tandridge informed the HPU about another case who had fallen ill on August 18. Tandridge and the HPU visited the farm on September 3; the number of confirmed and presumptive cases was now eight. On September 4, the farm voluntarily closed the petting barns. Case numbers continued to rise, but an OTC was not convened (by teleconference) until September 7. It held its second meeting on September 12, when there were 36 confirmed or presumptive cases. The farm closed voluntarily on that day. Media interest became strong on September 13. On September 15, the HPA announced it would set up an independent inquiry to evaluate the outbreak and its management and to consider the regulatory framework and control of risks relating to open farms. The last primary case (infected at the farm) fell ill on September 18, and the last secondary case (infected from contact with a primary case) fell ill on September 22. Transmission on the farm ceased when the petting barns closed. Ninety-three people were infected (91 laboratory-confirmed), with 65 primary cases, 13 secondary cases, and 15 asymptomatic cases. Twenty-seven patients were hospitalized, and 17 developed HUS: ten aged 1-4 years and seven aged 5-9 years. Eight patients needed dialysis, and some have been left with permanent kidney damage. The Pediatric Nephrology Unit at the Evelina Hospital in London serves the whole of South East England. In an average year, it treats five to ten HUS cases. It treated seven cases in September 2009 because of the outbreak. Its facilities were stretched to the maximum. Many E. coli $\mathrm{O} 157$ isolates were made on the farm: 25 from ruminants, four from pigs, three from the Shetland pony, one from a rabbit, and two from bird's nest samples from the main barn and from bark chipping from a bridge and tower in the adventure playground, straw bedding, dust from a metal railing, a pig pen, and a goat pen. All these isolates and the ones from the human cases had variable number tandem repeat profiles indicating they all originated from a common source.

Professor George Griffin chaired the HPA independent investigation. ${ }^{5}$ It published interim recommendations in March 2010 and presented a draft final report to the HPA Board on May 26, 2010. It concluded that the OCT was convened exceptionally late and that there was a delay in instituting strict controls at the farm. If contact with ruminants had been stopped on the holiday weekend, or even on Tuesday, September 1, a substantial number of cases could have been prevented. In addition, communication with health care professionals was not discussed at the first OCT (on September 7), and the HPU did not send letters to general practitioners and hospitals until September 10. Pediatric renal units in South East England were not told about the outbreak. There was a lack of public health leadership. The regulatory regime for open farms, including Godstone, was very complex. The farms were inspected by staff from local authority departments of environmental health and trading standards, by Animal Health (an executive arm of the Department for Environment, Food and Rural Affairs), and by the Health and Safety Executive. The HPA, through its local HPU, was tasked to play a lead role in outbreak control, but it had no powers to close an operation. The report made 43 recommendations. Ones identified as particularly 
important were minimizing visitor contact with animal feces, raising public awareness about this risk, developing an approved code of practice for open farms, getting the regulators to work together, and performing research on rapid diagnosis and the reduction of the carriage of $E$. coli O157 in animals.

\section{Recent UK outbreaks}

An enhanced surveillance system for E. coli O157 and other Shiga toxin-producing E. coli started in England on January 1, 2009. ${ }^{25}$ It assisted in the identification of two outbreaks solely on the basis of an increase in a particular phage type in England and Wales.

Phage type 8 caused an average of 22 cases yearly in 2007-2008, 2008-2009, and 2009-2010. During December 2010 and January 2011, 50 cases were confirmed. ${ }^{26}$ An increase in cases also occurred in Scotland and Wales. Molecular subtyping showed that many isolates were identical, and an OCT was established. The outbreak lasted until August, with a total of 193 cases in England, 44 in Scotland, and 14 in Wales. Cases occurred over the whole of the United Kingdom, 69\% of which were in women. Interviews with 30 sufferers found a statistically significant association with the handling of raw leeks and of potatoes from sacks.

An increase in the number of infections caused by phage type 2 occurred in August 2013: 14 patients fell ill in England, four in Wales, and one in Scotland; 65\% were women. Descriptive epidemiology pointed to watercress from a particular retailer and supplier. Microbiological investigations on the watercress and its production sites were negative.

Another outbreak for which the source of infection remains unestablished is one that occurred in Belfast in October 2012. ${ }^{27}$ An epidemiological link between cases was eating at Flicks restaurant; 138 cases were confirmed. The OCT report remains unpublished, possibly for legal reasons.

Scotland probably has the highest incidence of $E$. coli O157 infection in the world. It has maintained this position for many years. North East Scotland usually has the highest incidence within the country. The circumstances surrounding the Rose Lodge outbreak in May 2012 offer a partial explanation. ${ }^{28}$ The nursery had 35 infants and children aged 2-5 years registered when the outbreak occurred. It is located in Aboyne, a small town in Aberdeenshire with much animal husbandry in the surrounding area and with many households having private water supplies. The index case was an infant who had probably been infected at home through contact with animal feces either in the surrounding environment or contaminating the domestic private water supply. When tested, the water from this supply was positive for $E$. coli (not E. coli O157) and coliforms. The infant's stools were also positive for Cryptosporidium. Three infants and two adults (one was asymptomatic) went on to be infected by person-to-person spread in the nursery, and one adult by person-to-person spread at home. All the isolates had the same relatively rare phage type and indistinguishable pulsed field gel electrophoresis types. One infant developed severe HUS with neurological damage; 20 months after his infection, he is blind and partially deaf and remains in hospital on dialysis with intravenous feeding.

\section{Discussion}

Outbreaks are as relevant to the science of food safety and zoonoses as earthquakes are to seismologists. Outbreak information has led to the quantitation of the infectious dose, the frequency of asymptomatic infection and personto-person spread, and the time of persistence in the environment, as well as the identification of routes of spread, food vectors, and the age groups most likely to develop HUS. Outbreaks have raised public and political concerns leading to the commissioning of investigations and reports, debates in Parliament, and legislative changes and have influenced the reform of regulatory bodies. A particularly important role in raising public awareness has been played by mothers: Julie Preen set up a fund raising trust in 1999 when her daughter Heather died of HUS (three-case outbreak at Dawlish Warren, source unestablished), and Sharon Mills (mother of Mason Jones) ${ }^{29}$ and Tracy Mock (mother of twins who visited Godstone Farm and developed HUS) gave powerful television interviews.

A universal response to tragedy is to say "lessons must be learned", but the events in South Wales in 2005 repeated those in central Scotland in 1996, so it would be wise to restrict the number of lessons. Two stand out: First, a speedy response is vital. HUS cannot be prevented once an infection has been established. Preventing primary cases by removing the source of infection is obvious, but preventing secondary cases by promulgating hygiene messages to the public is crucially important. ${ }^{30}$ Second, there is more to inspecting an operation like a food business than ticking boxes. Personal experience, and even intuition, ${ }^{31}$ is very important in detecting ill-intentioned but well-informed operators, ${ }^{32}$ such as William Tudor.

Internationally, the United Kingdom has been exceptional in having so many outbreaks linked to butchers (30 recorded between 1995 and $2004^{17}$ ). Unlike the United States, there have been very few cases resulting from the consumption of 
ground beef (which was the vector in $41 \%$ of US foodborne outbreaks between 1982 and $2002^{33}$ ). It is reasonable to suppose that such differences reflect local food preferences and culinary customs.

The enormous German E. coli O104:H4 outbreak in $2011^{34}$ demonstrated that $E$. coli evolves in real-time. It is likely that many predictions about Shiga toxin-producing $E$. coli will be wrong, but one certainty is that E. coli $\mathrm{O} 157$ in the United Kingdom has not gone away. Laboratories in England, Wales, and Scotland reported 1,039 human isolations in 1995 and 1,029 in 2012. The only good news is that it remains rare relative to other bacterial causes of gastroenteritis; for example, in 2012, the laboratories in these countries ${ }^{35}$ reported 71,365 isolations of Campylobacter.

\section{Disclosure}

The author reports no conflicts of interest in this work.

\section{References}

1. Escherich T. Die Darmbacterien des Sauglings. [The intestinal bacteria of infants]. In: Bollinger O, editor. Arbeiten aus dem Pathologischen Institut zu Munchen. Stuttgart, Germany: Ferdinand Enke; 1886:1-180. German.

2. O'Brien AD, Kaper JB. Shiga toxin-producing Escherichia coli: yesterday, today, and tomorrow. In: Kaper JB, O'Brien AD, editors. Escherichia coli O157:H7 and Other Shiga Toxin-Producing E. coli Strains. Washington, DC: American Society for Microbiology; 1998:1-11.

3. Tarr PI, Gordon CA, Chandler WL. Shiga-toxin-producing Escherichia coli and haemolytic uraemic syndrome. Lancet. 2005;365(9464):1073-1086.

4. Pennington H. Escherichia coli O157. Lancet. 2010;376(9750): $1428-1435$.

5. Review of the major outbreak of E. coli O157 in Surrey, 2009. Report of the Independent Investigation Committee June 2010. Available from: http://www.griffininvestigation.org.uk. Accessed: December 30, 2013.

6. Griffin PM, Tauxe RV. The epidemiology of infections caused by Escherichia coli O157:H7, other enterohemorrhagic E. coli, and the associated hemolytic uremic syndrome. Epidemiol Rev. 1991;13:60-98.

7. Taylor CM, White RH, Winterborn MH, Rowe B. Haemolytic-uraemic syndrome: clinical experience of an outbreak in the West Midlands. Br Med J (Clin Res Ed). 1986;292(6534):1513-156.

8. Morgan GM, Newman C, Palmer SR, et al. First recognized community outbreak of haemorrhagic colitis due to verotoxin-producing Escherichia coli O 157.H7 in the UK. Epidemiol Infect. 1988;101(1):83-91.

9. Smith HR, Rowe B, Adak GK, Reilly WJ. Shiga toxin (Verocytotoxin)producing Escherichia coli in the United Kingdom. In: Kaper JB, O'Brien AD, editors. Escherichia coli O157:H7 and Other Shiga Toxin-Producing E. coli Strains. Washington, DC: American Society for Microbiology; 1998:49-58.

10. Chalmers RM, Parry SM, Salmon RL, Smith RM, Willshaw GA, Cheasty T. The surveillance of vero cytotoxin-producing Escherichia coli O157 in Wales, 1990 to 1998. Emerg Infect Dis. 1999;5(4):566-569.

11. Kohli HS, Chaudhuri AK, Todd WT, Mitchell AA, Liddell KG. A severe outbreak of E. coli O157 in two psychogeriatric wards. J Public Health Med. 1994;16(1):11-15.

12. Upton P, Coia JE. Outbreak of Escherichia coli O157 infection associated with pasteurised milk supply. Lancet. 1994;344(8928): 1015.

13. Roberts JA, Upton PA, Azene G. Escherichia coli O157:H7; an economic assessment of an outbreak. J Public Health Med. 2000;22(1):99-107.
14. Goh S, Newman C, Knowles M, et al. E. coli O157 phage type 21/28 outbreak in North Cumbria associated with pasteurized milk. Epidemiol Infect. 2002;129(3):451-457.

15. Gillespie IA, Adak GK, O’Brien SJ, Bolton FJ. Milkborne general outbreaks of infectious intestinal disease, England and Wales, 1992-2000. Epidemiol Infect. 2003;130(3):461-468.

16. House of Commons Welsh Affairs Committee Third Report Session 1990-1991. Arrangements for Handling Serious Outbreaks of Food Poisoning in the Light of the Salmonella Outbreak in July and August 1989 in North Wales. HMSO 1991.

17. Pennington TH. The Public Inquiry into the September 2005 Outbreak of E. coli O157 in South Wales. Aberdeen: HMSO; 2009. Available from: http://wales.gov.uk/ecolidocs/3008707/reporten.pdf?skip=1\&lang=en. Accessed: December 30, 2013.

18. Pennington TH. VTEC: lessons learned from British outbreaks. Symp Ser Soc Appl Microbiol. 2000;29:90S-98S.

19. Pennington TH. When Food Kills. New York: Oxford University Press; 2003.

20. Pennington TH. The Pennington Group: Report on the Circumstances Leading to the 1996 Outbreak on Infection with E. Coli O157 in Central Scotland, the Implications for Food Safety and the Lessons to be Learned. Edinburgh: HM Stationery Office; 1997.

21. Cox GL. Determination into the E. Coli O157 Fatal Accident Inquiry. Airdrie: Sheriffdom of South Strathclyde, Dumfries and Galloway; 1998.

22. Milne LM, Plom A, Strudley I, et al. Escherichia coli O157 incident associated with a farm open to members of the public. Commun Dis Public Health. 1999;2(1):22-26.

23. Howie H, Mukerjee A, Cowden J, Leith J, Reid T. Investigation of an outbreak of Escherichia coli O157 infection caused by environmental exposure at a scout camp. Epidemiol Infect. 2003;131(3):1063-1069.

24. Strachan NJ, Dunn GM, Ogden ID. Quantitative risk assessment of human infection from Escherichia coli $\mathrm{O} 157$ associated with recreational use of animal pasture. Int J Food Microbiol. 2002;75(1-2):39-51.

25. Launders N, Byrne L, Adams N, et al; Outbreak Control Team. Outbreak of Shiga toxin-producing E. coli O157 associated with consumption of watercress, United Kingdom, August to September 2013. Euro Surveill. 2013;18(44):20624.

26. National increase in vero cytotoxin-producing E. coli O157 infection in England and Wales. Health Protection Rep. 2011;5(6):1-3.

27. Northern Ireland Assembly Committee for Health, Social Services and Public Safety. Official Report (Hansard): E. coli outbreak. Ireland: Northern Ireland Assembly; 2012. Available from: http://www.niassembly.gov.uk/Documents/Official-Reports/Health/2012-2013/121024_E. ColiOutbreak.pdf. Accessed: December 30, 2013.

28. Incident Management Team. Outbreak of E. coli O157 infection at Rose Lodge Nursery, Aboyne. Aberdeen: NHS Grampian; 2012. Available from: http://www.nhsgrampian.org/files/ Item10.4.1CGCReportIMTReport.pdf. Accessed: May 21, 2014.

29. Pennington TH. The role of the media in public health crises: perspectives from the UK and Europe. In: Bennett P, Calman K, Curtis S, Fischbacher-Smith D, editors. Risk Communication and Public Health. 2nd ed. Oxford: Oxford University Press; 2010:81-96.

30. Werber D, Mason BW, Evans MR, Salmon RL. Preventing household transmission of Shiga toxin-producing Escherichia coli O157 infection: promptly separating siblings might be the key. Clin Infect Dis. 2008;46(8):1189-1196.

31. Polanyi M. Personal Knowledge. New York: Harper and Row; 1964.

32. Baldwin R. Rules and Government. Oxford: Clarendon Press; 1996.

33. Rangel JM, Sparling PH, Crowe C, Griffin PM, Swerdlow DL. Epidemiology of Escherichia coli O157:H7 outbreaks, United States, 1982-2002. Emerg Infect Dis. 2005;11(4):603-609.

34. STEC Workshop Reporting Group. Experiences from the Shiga toxin-producing Escherichia coli O104:H4 outbreak in Germany and research needs in the field, Berlin, November 28-29, 2011. Euro Surveill. 2012;17(7):20091.

35. Laboratory reports, Campylobacter, 2012. Public Health England; Health Protection Scotland. 2013. 
Infection and Drug Resistance

Dovepress

\section{Publish your work in this journal}

Infection and Drug Resistance is an international, peer-reviewed openaccess journal that focuses on the optimal treatment of infection (bacterial, fungal and viral) and the development and institution of preventive strategies to minimize the development and spread of resistance. The journal is specifically concerned with the epidemiology of antibiotic

resistance and the mechanisms of resistance development and diffusion in both hospitals and the community. The manuscript management system is completely online and includes a very quick and fair peerreview system, which is all easy to use. Visit http://www.dovepress.com/ testimonials.php to read real quotes from published authors.

Submit your manuscript here: http://www.dovepress.com/infection-and-drug-resistance-journal 